To the Editors:

\title{
Inguinal ureteral hernia
}

\section{B Sayanthan', G H Rathnasiri², A D Silva²}

Ceylon Medical Journal 2016; 61: 201

http://doi.org/10.4038/cmj.v61i4.8396

A 63-year-old previously healthy male was admitted with a large reducible left inguinal hernia. He was otherwise asymptomatic. The routine preoperative investigations including renal functions were normal. A routine hernia repair was conducted under spinal anaesthesia. Intra-operatively we found a para-peritoneal sliding type hernia of left ureter which was injured during hernia sac dissection. We inserted a double $\mathrm{J}$ stent into the injured left ureter and completed the hernia repair. Recovery was uneventful with normal urine output and renal function during post-operative period. Postoperative X-Ray KUB (Figure 1) and CT-IVU were normal. Urinary stent was removed after 6 weeks and he recovered without any complication.

Inguinal hernia of ureter (IHU) is a rare condition. Inguinal hernia of bladder is more common than IHU [1]. Inguinal hernia of ureter can be of two types, para peritoneal type with hernia sac covering the ureter and extra peritoneal type with no hernia sac around the ureter [2]. Since the ureter is a content of the hernia sac, in para peritoneal type IHU, it is known as a sliding hernia. Pre-operative diagnosis of IHU using imaging studies will prevent intra-operative injury to ureter. However, doing imaging studies before each hernia repair cannot be justified considering the rarity of IHU, feasibility and cost of imaging studies. Therefore, IHU is commonly diagnosed intra-operatively by visualising the ureter or post-operatively by leakage of urine from the wound site [2].

\section{Conflicts of interest}

There are no conflicts of interest.

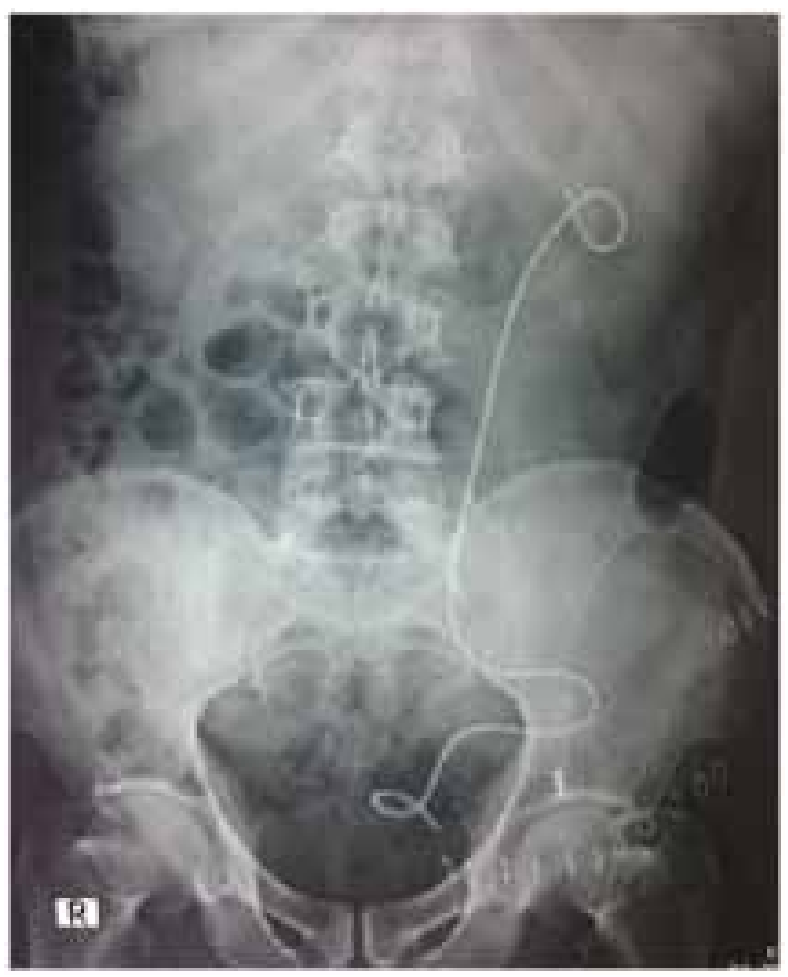

Figure 1. Post-operative X-Ray.

\section{References}

1. Mallouh C, Pelmann C. Scrotal herniation of the ureter. J Urol 1971; 106: 38-41.

2. Zmora O, Schachter PP. Sliding inguinal hernia containing the ureter: a case-report. J Urol 1996; 155: 1387-8.

${ }^{1}$ Department of Surgery, Faculty of Medicine, University of Jaffna and ${ }^{2}$ General Surgery Unit, National Hospital, Sri Lanka. Correspondence: BS, e-mail: <srisayan@yahoo.com>. Received 9March 2016. 